
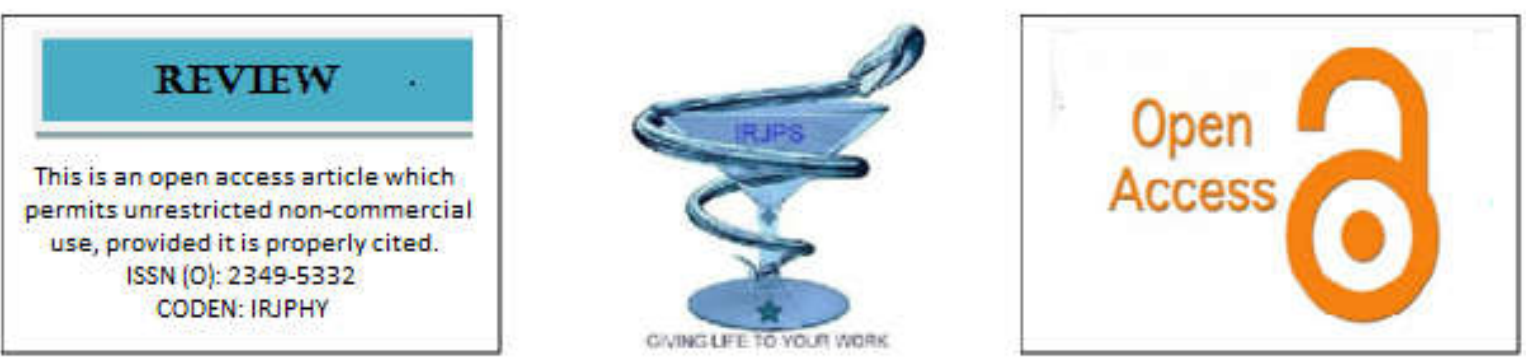

\title{
AN OVERVIEW ON NATURAL POLYMER BASED MUCOADHESIVE BUCCAL FILMS FOR CONTROLLED DRUG DELIVERY
}

\author{
Ankita Khade*, Vidya Sabale, Gunjan Gadge, Ujwala Mahajan \\ Dadasaheb Balpande College of Pharmacy, Besa, Nagpur, Maharashtra, India
}

Submitted on: 28.03.19;

Revised on: 23.04.19;

Accepted on: 29.04.19

\begin{abstract}
Mucoadhesion is the process where polymers attach to biological substrate or a synthetic or natural macromolecule to mucus or an epithelial surface. When the biological substrate is attached to a mucosal layer then this phenomenon is known as mucoadhesion. The substrate possessing bioadhesive polymer can help in drug delivery for a prolonged period of time at a specific delivery site.Natural polymers have recently gained importance in pharmaceutical field. Mucoadhesive polymers are used to improve drug delivery by enhancing the dosage form's contact time and residence time with the mucous membrane. The studies of mucoadhesive polymers provide a good approach of mucoadhesion and some factors which have the ability to affect the mucoadhesive properties of a polymer. Both natural and synthetic polymers are used for the preparation of mucoadhesive buccal films. Various natural polymers which can be used in mucoadhesive buccal films are chitosan, sodium alginate, tragacanth, gelatin and guar gum etc. This review is an effort to summarize the work done till date and to show the future pathway of mucoadhesive buccal films preparation using natural polymer.
\end{abstract}

KEY WORDS: Mucoadhesive, Natural polymer, Drug delivery

Corresponding Author: Ankita Khade E-mail: ankita.khade@outlook.com

Phone: +91-7030909724
Indian Research Journal of Pharmacy and Science; 20(2019)1812-1824; Journal Home Page: https://www.irjps.in DOI: 10.21276/irjps.2019.6.1.7 


\section{INTRODUCTION}

Mucoadhesion can be defined as the state in which two materials adhere to each other for extended period of time with the help of interfacial forces. ${ }^{1}$ When one of these materials is biological in nature the process is known as bioadhesion. ${ }^{2}$ Mucoadhesion is the process of binding a material to the mucosal layer of the body. ${ }^{3}$ Utilising natural and synthetic polymers, mucoadhesive drug delivery is a method of controlled drug release which allows for intimate contact between the polymer and a target tissue. Mucoadhesive drug delivery systems are delivery systems which utilize the property of bioadhesion of certain polymers which develop intoadhesive on hydration and hence are able to be used for targeted delivery of the drug to a particular region of body for the extended period of time. ${ }^{4,5,6}$

The concept of mucoadhesion was introduced in the controlled release drug delivery systems in the early $1980 \mathrm{~s}^{7,8}$ Controlled release system provides continuous drug release at a predetermined rate and for a predetermined time. These systems have been developed to facilitate better control of drug release over the time, to assist drug in crossing physiological barrier, to protect drug from pre mature elimination, and to propel the drug to the desired site of action while minimizing drug exposure elsewhere in the body. Control release systems may also increase patient compliance by reducing frequency of administration and may add commercial value to the marketed drug by extending patent protection. Finally, use of controlled release technology may reduce variability of performance of drug products. ${ }^{9,} 10$

\section{MECHANISMS OF MUCOADHESION}

The mechanism of adhesion of certain macromolecules at the surface of a mucous tissue is not well understood yet. Attraction and repulsion forces arise and for a mucoadhesion to be successful, the attraction forces must dominate. ${ }^{11,12}$ Each step can be facilitated by the nature of the dosage form and how it is administered. For example, a partially hydrated polymer can be absorbed by the substrate because of the attraction by the surface water. ${ }^{13}$ Thus, the mechanism of mucoadhesion is generally divided in two steps, the contact stage and the consolidation stage (Figure 1).

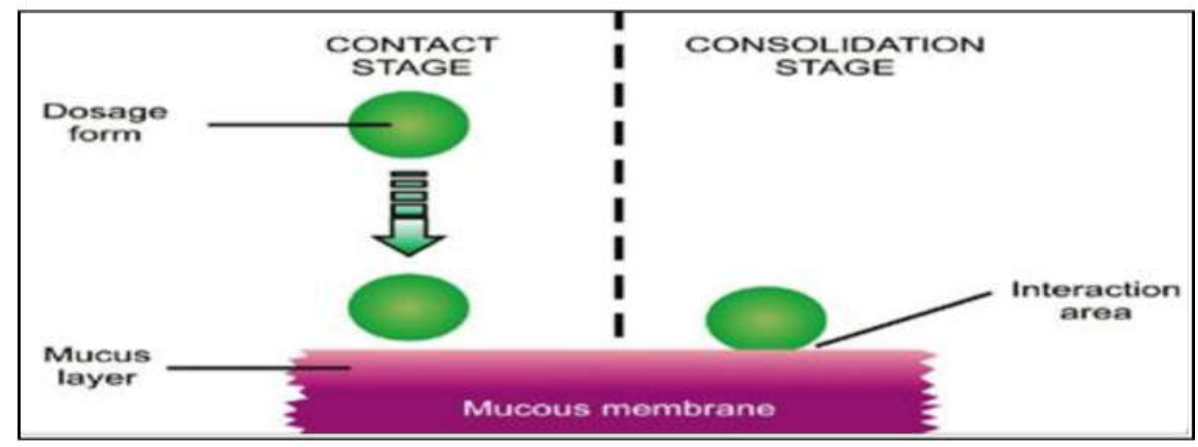

Figure1: Mechanism of Mucoadhesion

The first stage is characterized by the contact between the mucoadhesive and the mucous membrane with spreading and swelling of the formulation, initiating its deep contact with the mucus layer. ${ }^{14,15}$ In some cases, such as ocular or vaginal formulations, the delivery system is automatically attached over the membrane. In other cases, the deposition is promoted by the aerodynamics of the organ to the system administered such as nasal route. Peristaltic motions can contribute to this contact, but there is little evidence in the literature showing appropriate adhesion. ${ }^{16}$
Additionally, an undesirable adhesion in the throat can occur. In this case, mucoadhesion can be explain by peristalsis, the motion of organic fluids in the organ cavity or by Brownian motion. If the particle approaches the mucous surface, it will come into contact with repulsive forces (osmotic pressure, electrostatic repulsion, etc.) and attractive forces (Vander Waals forces and electrostatic attraction). Therefore, the particle have toovercome this repulsive barrier. ${ }^{17,18}$

In the consolidation step (Figure 1), the mucoadhesive materials are activated by the presence 
of moisture. Moisture plasticizes the system, allowing the mucoadhesive molecules to break free and to link up by weak Van der Waals and hydrogen bonds. ${ }^{19}$ Essentially, there are two theories explaining the consolidation step: the diffusion theory and the dehydration theory. ${ }^{20}$ According to diffusion theory, the mucoadhesive molecules and the glycoproteins of the mucus mutually interact by means of interpenetration of their chains and the building of secondary bonds. ${ }^{21}$

The mucoadhesive device has features whichfavor both chemical and mechanical interactions. For example, molecules with hydrogen bondstructural groups $(-\mathrm{OH},-\mathrm{COOH})$, with an anionic surface charge, high molecular weight, flexible chains and surface-active properties, which introduce its spread throughout the mucus layer, can present mucoadhesive properties. ${ }^{22}$ According to dehydration theory, materials that are able to readily jellify in anaqueous environment, when placed in contact with the mucus can cause its dehydration due to the difference of osmotic pressure. ${ }^{23}$ This process leads to the mixture of formulation and mucus and thus increase contact time with the mucous membrane. Therefore, it is water motion that leads to consolidation of the adhesive bond and not the interpenetration of macromolecular chains. However, the dehydration theory is not applicable for solid formulations or highly hydrated forms. ${ }^{20}$

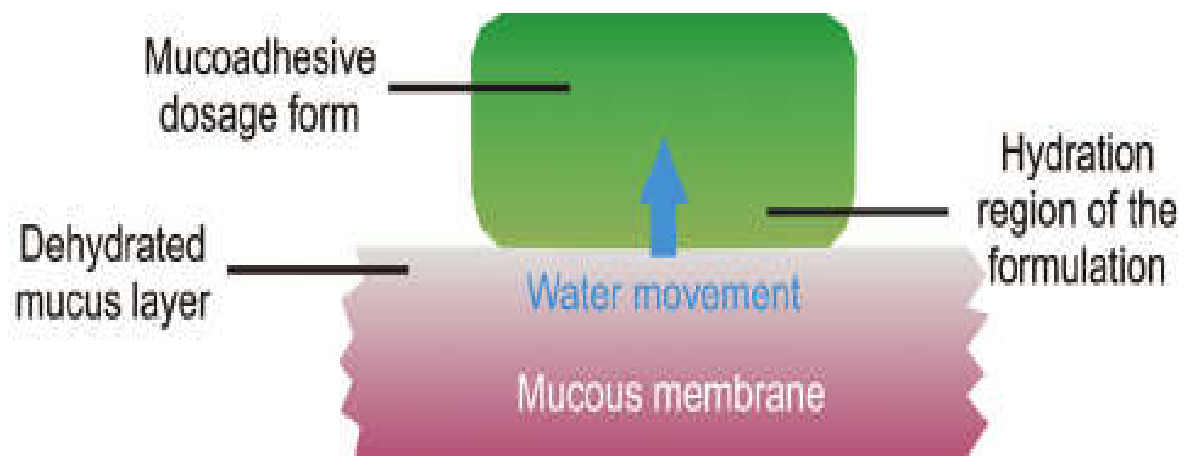

Figure 2: Dehydration theory of Mucoadhesion

The term bioadhesion refers to any bond form between two biological surfaces or a bond between a biological and a synthetic surface. ${ }^{24}$ In case bioadhesive drug delivery, the term bioadhesion is used to describe the adhesion between polymers, either synthetic or natural. In cases, the bond is formed with mucus the term mucoadhesion may beused synonymously with bioadhesion. Mucoadhesion can be defined as a state in which two components of which one is biological origin, are held together for extended period of time with the help of interfacial forces. ${ }^{25,26}$ Generally speaking, bioadhesion is a term which broadly includes adhesive interactions with any biological or biologically derived substance, and mucoadhesion is used when the bond is formed with a mucosal surface.

\section{THEORIES OF MUCOADHESION}

Mucoadhesion is a complex process and numerous theories have been proposed to explain the mechanisms involved. ${ }^{27,28}$

\section{Electronic theory}

This theory is based on the fact that both mucus layer and biological materials have opposite electrical charges that able to create double electronic layer at the boundary and thus helps in determination of mucoadhesive strength. ${ }^{29,30}$

\section{Wetting theory}

Liquid or less viscous molecules enter into mucous surface and fix themselves by counteract the surface tension at the interface. This property related to contact angle, wetting and spreadability capacity of molecule. Contact angle $(\theta)$ and interfacial tension $(\gamma)$ can be determined from following equation: ${ }^{31}$

$\gamma \mathrm{SG}=\gamma \mathrm{SL}+\gamma \mathrm{LG} \cos \mathrm{S}=\gamma \mathrm{SG}-(\gamma \mathrm{SL}-\gamma \mathrm{LG})$

Where, $\gamma L G$ is liquid-gas surface tension, $\gamma \mathrm{SL}$ is solid-liquid surface tension and $\gamma \mathrm{SG}$ is solid-gas surface tension. 


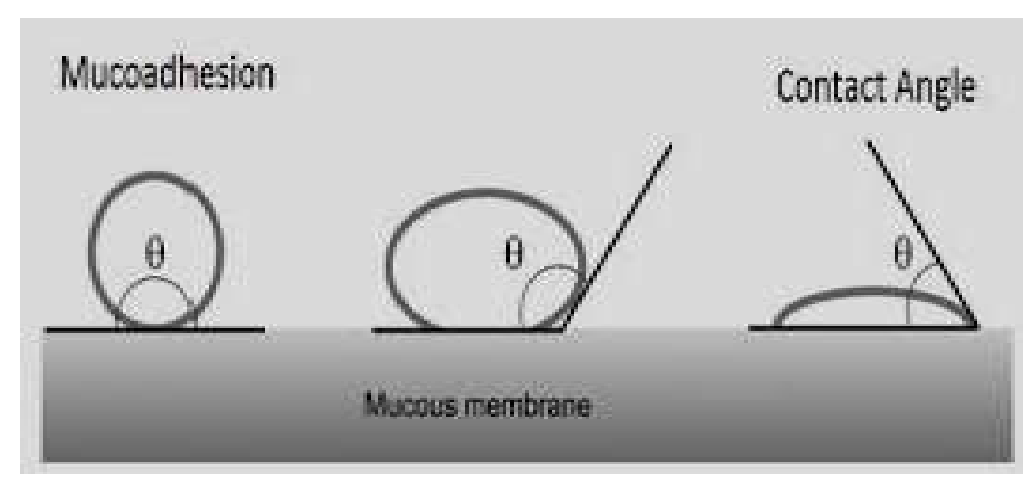

Figure 3: Wetting theory of mucoadhesion

\section{Diffusion Theory}

These theories suggest that mucoadhesive polymer diffuses into mucus layer by breaking glycoprotein chain complex. This diffusion is time dependent and depends on diffusion coefficient and molecular weight of both phases. ${ }^{32,33}$

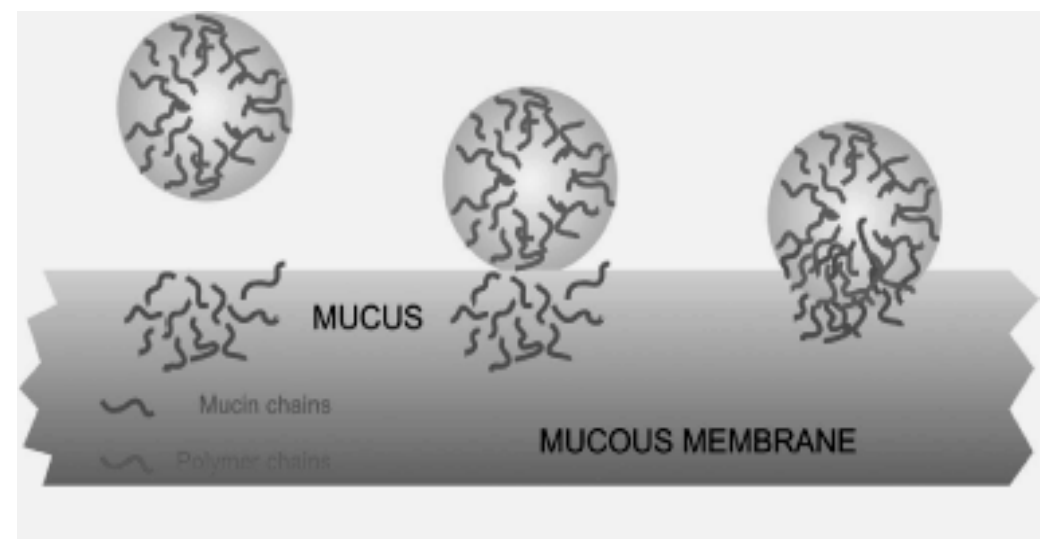

Figure 4: Diffusion theory of mucoadhesion

\section{Adsorption Theory}

Weak Vander Waals forces and hydrogen bond mediated adhesion involved in adsorption theory is most accepted theory of mechanism of mucoadhesion. It involves primary and secondary bonding in exhibiting semi permanent surface interactions. ${ }^{34,35}$

\section{Fracture Theory}

This is second mainly accepted theory, which explain the forces required to separate the two surfaces of following adhesion. This forces is called as tensile stress or fracture strength and can be determined by following equation:

\section{$\mathrm{Sm}=\mathrm{Fm} / \mathrm{Ao}$}

Where Sm: Tensile stress, Fm: maximum force of detachment and Ao: surface area $\mathrm{OR} \mathrm{Sf}=(\mathrm{gcE} / \mathrm{c}) 1 / 2$ Where Sf: fracture strength, gc: fracture energy, E:
Young's modulus of elasticity and c: critical crack length.

\section{Buccal drug delivery}

The lip, tongue, cheek, soft palate, hard palate, and floor of mouth include oral cavity. Mucous layer consist of three layers: outer epithelium, middle basement and inner connective tissues. $100 \mathrm{~cm}$ total area of the oral cavity consists of about one third of buccal surface of $0.5 \mathrm{~mm}$ thickness epithelium. ${ }^{36}$ About 0.5 to 2 litre of saliva runs into mucosal surface. $\mathrm{pH}$ of salvia vary between the 5.5 to 7 depending on its flow rate. A neutral lipid like ceramides consisting epithelium is keratinized epithelium while polar lipids like cholesterol sulphate and glucosylceramidesis non-keratinized epithelium. ${ }^{37}$ Non-keratinized region of buccal is most suitable region for drug administration specially proteins/peptides than nasal, rectal and vaginal drug 
delivery. Drug enters into systemic circulation through jugular ducts via network of blood vessels. ${ }^{38}$

\section{ORAL MUCOSA}

The anatomy and physiology of the oral mucosa have been extensively reviewed in several publications. ${ }^{39,40-42}$ There are three distinctive layers of the mucosa are the epithelium, basement membrane, and connective tissues. The oral cavity is lined with the epithelium, which lies the supporting basement membrane. The basement membrane is turn, supported by connective tissues. The epithelium, as a protective layer for the tissues under, is divided into (a) non-keratinized surface in the mucosal lining of the soft palate, the ventral surface of the tongue, floor of mouth, alveolar mucosa, vestibule, lips, and cheeks, and (b) keratinized epithelium which is found in the hard palate and nonflexible regions of the oral cavity. ${ }^{41}$ The epithelial cells, originate from the basal cells, mature, change their shape and increase in size while moving towards the surface. The thickness of buccal epithelium in humans, dogs, and rabbits has been determined to be approximately $500-800 \mathrm{Am} .{ }^{43}$ The basement membrane forms a distinctive layer between the connective tissues and the epithelium. It provides the required adherence between the epithelium and the underlying connective tissues, and functions as a mechanical support for the epithelium. ${ }^{44}$ The underlying connective tissues provides many mechanical properties of oral mucosa. The buccal epithelium is classified as a no keratinized tissue. ${ }^{45}$ It is penetrate by tall and conicalshaped connective tissues. These tissues, which are also referred to as the lamina propria, consist of collagen fibers, a supporting layer of connective tissues, blood vessels, and smooth muscles. ${ }^{46}$ The poor arterial blood supply to the oral mucosa is derived from the external carotid artery. In buccal artery, some terminal branches of the facial artery, the posterior alveolar artery, and the infraorbital artery are the major sources of blood supply to lining of the cheek in the buccal cavity. ${ }^{47} \mathrm{~A}$ gel-like secretion known as mucus, which contains generally water insoluble glycoproteins, covers the entire oral cavity. Mucus is bound to the apical cell surface and acts as a protective layer to the cells below ${ }^{48}$ It is also a viscous elastic hydrogel, and primarily consists of $1-5 \%$ of the above mentioned water insoluble glycoproteins, $95-99 \%$ water, and several other components in small quantities, such as proteins, enzymes, electrolytes, and nucleic acids. This composition can vary based on the origin of the mucus secretion in the body. ${ }^{49,50}$

\section{Buccal films ${ }^{2}$}

Buccal films are most recently developed dosage form for buccal administration. They have gained importance as efficacious and novel drug delivery systems and are cost effective with a good patient compliance. ${ }^{51}$ Buccal films are implied for attachment to the buccal mucosa, they can formulate to exhibit local as well as systemic action. Buccal film may preferred over buccal tablet, in terms of flexibility and comfort. Buccal films have direct access to the systemic circulation through the internal jugular vein, which bypasses the drug from the hepatic first pass metabolism leading to high bioavailability. ${ }^{52}$ This can be defined as a dosage form that employs a water dissolving polymer, which allows the dosage form to quickly hydrate, adhere and dissolve when placed on tongue, or the oral cavity, which results in systemic drug delivery. The major property of the buccal film is that due to the large surface area of film, it allows quick wetting of the film which accelerates absorption of the drug quickly when compared to tablets. These films have one bioadhesive layer containing the drug and a backing membrane layer that keeps drug from flowing towards the buccal membrane and not the mouth. The film then dissolves within 15-30 min after application. ${ }^{53}$

Mucoadhesive films leads direct access to the systemic circulation through the internal jugular vein bypasses drugs from the hepatic first pass metabolism leading to high bioavailability. Buccal route is an attractive route of administration for systemic drug delivery system. Buccal bioadhesive films, releasing topical drugs in the oral cavity at a slow and predetermined rate, provide distinct advantages over traditional dosage forms for treatment of many diseases. ${ }^{54}$

\section{Advantages $^{55}$}

- The mucosal lining of buccal tissue provides much milder environment for drug absorption. 
- It is richly vascularized and more available for the administration and removal of dosage form.

- Buccal drug delivery system has a high patient acceptability compared to other nonoral route of drug administration.

- Avoiding acid hydrolysis in gastrointestinal tract and bypassing the "First-Pass" effect are some benefits of this route of drug delivery.

- Rapid cellular recovery and achievement of the localized site on the smooth surface of buccal mucosa are among the other advantages of this route of drug delivery.

\section{Disadvantages $^{56}$}

- This route of drug delivery is the low permeability of the buccal membrane specifically when compared to sublingual membrane. ${ }^{57}$

- The continuous secretion of the saliva (0.5-2 $1 /$ day) leads to subsequent dilution of the drug. ${ }^{58}$

- Swallowing the saliva can also potentially lead to the loss of dissolved or suspended drug.

\section{MANUFACTURING TECHNIQUES}

Following techniques are used to manufacturing of buccal film

\section{Film casting technique}

Film casting method is one of the most generally used methods for the manufacturing of buccal film. It is the advantages of easy preparation, being cheap and can easily be adopted at lab scale. It involves following steps. ${ }^{59,60}$

Prepare casting solution

Deaerate the solution

Pour the solution into a mold

Dry the casting solution

Cut final dosage form containing desired amount of drug

\section{Hot melt extrusion technique}

In this method mixture of pharmaceutical ingredients is melted. In order to reach homogeneous mixture in various dosage form like tablets, granules, pallets or film, the melted material is pushed to pass through a small opening (orifice of a die). ${ }^{61-62}$ Although this method is rarely used for the manufacture of film but there are certain evidence in the literature that this method can be use for film preparation. ${ }^{63-66}$

\section{Mucoadhesive polymers}

Mucoadhesive polymer-based drug delivery systems were first utilized by Nagai and collaborators as carriers for local treatment to the buccal cavity. ${ }^{67,68}$ Mucoadhesive polymers used to produce controlled release dosage forms that are able to adhere to the buccal membrane for extended periods of time. Mucosal adhesive materials have been identified and investigated in previous work. These materials are generally hydrophilic macromolecules containing numerous hydrogen bond forming groups, including hydroxyl and carboxyl groups that interact with functional groups in the mucus layer to produce secondary chemical bonds. ${ }^{69}$ Mucoadhesive drug delivery systems are being explore for the localization of the active agents to a particular location/ site. Polymers have played an important role in design such systems so as to increase the residence time of the active agent at the desired location. ${ }^{70}$ Polymers should present suitable chain flexibility at the $\mathrm{pH}$ and ionic strength of the mucus this expected to favor interpenetration and mucoadhesion. ${ }^{71}$ Mucoadhesive polymers that are adhere to the mucin-epithelial surface can be suitably divided into three broad classes:

- Polymers that develop into sticky when placed in water and their mucoadhesion to stickiness.

- Polymers that are adhere through nonspecific, non-covalent interactions, those are primarily electrostatic in nature (although hydrogen and hydrophobic bonding may be significant).

- Polymers that binds to specific receptor site on tile selfsurface.

\section{Characteristics of an ideal mucoadhesive Polymer $^{72,73}$}

An ideal mucoadhesive polymer has the following characteristic:

1. They should be non-toxic and non-absorbable from the gastrointestinal tract. 
2. It should be non-irritant to the mucous membrane.

3. It should be preferably form a strong non-covalent bond with the mucin-epithelial cell surfaces.

4. It should adhere quickly to tissue and should have some site-specificity.

5. It should allow daily absorption to the drug and offer no hindrance to its release.

6 . The polymer must not decompose on storage.

7. The cost of polymers should not be high so that the prepared dosage form remains competitive.

\section{Classification of polymers ${ }^{74}$}

In general, adhesive polymers can be classified as synthetic vs naturals, water-soluble vs. water-insoluble and charged vs. uncharged polymers. In the class of synthetic polymers, poly (acrylic acid), cellulose ester derivatives, polymethacrylate derivatives are the current choices. Chitosan and various examples of gums such as gaur and karaya are classified as semi-natural/natural bioadhesive polymers. Poly (acrylic acid), a linear or random polymer and polycarbophil a swellable polymer represent water-soluble and water-insoluble polymers, respectively. The charged polymers are divided into cationic and anionic polymers such as chitosan and polycarbophil, while hydroxypropylcellulose is an example of uncharged bioadhesivepolymers. ${ }^{[75]}$

Natural polymers ${ }^{\text {[74] }}$

Natural polymers have recently attracted the attention of scientists and technologists because of the advantages that these polymers provide over conventional reinforcement materials, and the development of natural polymer composites has been a subject of interest for the past few years. ${ }^{74,75,76,77}$ These natural polymers are low-cost polymers with low density and high specific properties. They are readily available and their specific properties are comparable to synthetic polymer used for reinforcements. Natural polymers obtained from plants have diverse applications in drug delivery as a disintegrant, emulsifying agent, suspending agents and as binders. ${ }^{78}$ Natural gums are hydrophilic carbohydrate polymers of high molecular weights. Natural polymers being safe,biocompatible and biodegradable are preferred over synthetic polymers. These polymers can form non-covalent bonds with the mucin molecules because of the presence of number of carboxyl, hydroxyl and amino groups.

For example: acrylic includes acrylic acid, acrylamide and maleic anhydride polymers.

\section{Advantages of natural polymers ${ }^{74}$}

- Biodegradable: Biodegradable polymers are produced by all living organisms. They represent renewable source and they have no adverse impact on humans or environmental health.

- Biocompatible and non-toxic: Chemically, almost all of these plant materials are carbohydrates composed of repeating sugar (monosaccharides) units. Hence, they are non- toxic.

- Low cost: It is cheaper to use natural sources. The production cost is also much lower as compared with that for synthetic material.

- Environmental: Friendly, the processing of gums and mucilages from different sources are easily collected in different seasons in large quantities due to the simple production processes involved.

- Local availability (especially in developing countries): in developing countries, governments promote the cultivation of plants for production of guar gum and tragacanth because of the wide applications in a variety of industries.

- Better patient tolerance as well as public acceptance: There is less chance of side effects and adverse effects with natural materials compared to synthetic one.

- Edible sources: Most of the gums and mucilages are obtained from edible sources.

\section{Disadvantages of natural polymers ${ }^{73,79}$}

- Microbial contamination: The equilibrium moisture content present in the gums and mucilages is normally $10 \%$ or more and, structurally, they are carbohydrate, during production, they are exposed to the external environment and, so there is a chances of microbial contamination. However, this can 
be prevented by good handling and the use of preservatives.

- Batch to batch variation: manufacturing of synthetic gums is a controlled procedure with fixed quantities of ingredients, while the production of gums and mucilages is dependent on environmental and seasonal factors.

- Uncontrolled rate of hydration: due to different in collection of natural materials at different times, as well as differences in region, species, and climate conditions the percentage of chemical constituents present in a given material may vary. There is need to develop suitable monographs on available gums and mucilages.

- Reduced viscosity on storage: Normally, when gums and mucilages come into contact with water there is an increase in viscosity of the formulations. Due to the complex nature of gums and mucilages (monosaccharides to polysaccharides and their derivatives), it has been found that after storage there is decrease in viscosity.

\section{EVALUATION}

\section{Film weight and thickness ${ }^{80,81,82}$}

The weight of films $\left(1 \times 1 \mathrm{~cm}^{2}\right)$ was measured using digital balance and the average weight $(n=3)$ was calculated. Thickness of each film was measured using Vernier caliper held at different positions on the films and the average was calculated.

\section{Folding endurance ${ }^{83,84}$}

The folding endurance of the films was determined by repeatedly folding each film at the same place until it broke or for a maximum of 300 times. The number of time the film could be folded at the same place without breaking give the value of the folding endurance. The mean value of three observations was calculated.

\section{Drug content}

Drug content is an important parameter to assure the availability and uniformity of drug in a film. ${ }^{85}$ Three films $\left(1 \times 1 \mathrm{~cm}^{2}\right)$ were taken in separate volumetric flasks; $10 \mathrm{ml}$ methanol was added and sonicated for $10 \mathrm{~min}$. The solutions were filtered with whatmann filter paper, diluted suitably and analyzed at $306 \mathrm{~nm}$ in a UV spectrophotometer. The drug concentration in each film was determined by extrapolating from standard curve. Average drug content of three films was estimated.

\section{Surface $\mathbf{p H} \mathbf{H}^{86}$}

Buccal films were left to swell for $2 \mathrm{~h}$ in $5 \mathrm{ml}$ phosphate buffer of $\mathrm{pH} 6.8$ at RT. Films were removed and $\mathrm{pH}$ was measured by placing a combined glass electrode of $\mathrm{pH}$ meter (Universal enterprises, India) on the surface of the wetted film. The mean of three observations was calculated.

\section{Mucoadhesive strength ${ }^{87,88}$}

Mucoadhesive studies was carried out using mucoadhesion test apparatus based on the principle of double beam physical balance using 3\% (w/v) mucin solution. Ten micro liters of mucin solution were applied on two different coverslips. The opposite side of each coverslip was stuck by a double sided tape to the upper and lower surface of the left hand setup of the balance, respectively. The films of $1 \times 1 \mathrm{~cm}^{2}$ were applied on a coverslip present on the lower surface of left hand side balance. The coverslip present on the upper surface was brought in contact with the film placed on the coverslip present on the lower surface. This was done by removing $5 \mathrm{gm}$ weight from the right pan of the balance. The balance was kept in this position for $3 \mathrm{~min}$ and then slowly weight was added on the right pan until the film detached from the coverslip. The excess weight on the pan i.e. total weight minus $5 \mathrm{gm}$ is force required for detaching the film. This gave the mucoadhesive strength of the film in ' $\mathrm{g}$ '. The maximum adhesive force was recorded as average of three measurements.

\section{Swelling ${ }^{89,90}$}

After determination of the film weight, the samples were allowed to swell in phosphate buffer of $\mathrm{pH} 6.8$ until $8 \mathrm{~h}$. Increase in film weight $(\mathrm{n}=3)$ was determined at different time intervals by removing the film from phosphate buffer and blotted with filter paper to remove excess of water. The percentage 
swelling $(\% \mathrm{~S})$ was calculated using following equation:

Percent Swelling $(\% \mathrm{~S})=(\mathrm{Xt}-\mathrm{Xo} / \mathrm{Xo}) \times 100$,

where $\mathrm{Xt}$ is the weight of swollen film after time $\mathrm{t}$, $\mathrm{Xo}$ is the initial weight of the film.

\section{In vitro drug release ${ }^{91}$}

A standard USP paddle apparatus (Electro lab Dissolution apparatus) was employed to evaluate in vitro drug release. The area of film $(n=3)$ equivalent to $10 \mathrm{mg}$ of drug was stuck from corners and sides at the base of dissolution vessel with double sided tape; the vessel was filled with $500 \mathrm{ml}$ PBS of $\mathrm{pH} 6.8$ maintained at $37 \pm 0.5^{\circ} \mathrm{C}$ and stirring at $50 \mathrm{rpm}$. Samples were collected at predetermined time intervals till $8 \mathrm{~h}$ and replaced with an equal volume of fresh PBS pH 6.8. Resveratrol concentration was determined by using UV Spectrophotometer. Mechanism of drug release was identified by using various kinetic models including zero order, first order, Korsmeyer-Peppas, Hixson-Crowell and Higuchi. The data of in vitro drug release was fitted in these models and evaluated by means of linear regression analysis.

\section{Ex vivo histopathological examination of buccal mucosa $^{92,93}$}

Histopathological changes were examined on goat buccal mucosa using the optimized formulation. Buccal pouch was obtained from local slaughterhouse within $2 \mathrm{~h}$ of sacrifice and trimmed to get a layer of mucous membrane. The tissue was mounted on a Franz diffusion cell assembly with phosphate buffer saline $\mathrm{pH} \quad 6.8$ in receiver

\section{REFERENCES}

1. Yadav V, Gupta AB, Kumar R, Yadav JS, Kumar B. Mucoadhesive Polymers: Means of Improving the Mucoadhesive Properties of Drug Delivery System. J. Chem. Pharm. Res., 2010; 2(5):418-432.

2. Mansuri S, Kesharwani P, Jain K, Tekade RK, Jain NK. Mucoadhesion: A promising approach in drug delivery system. React Fract Poly, 2016; 152: 162-163. compartment. The study was carried out for $8 \mathrm{~h}$ using control and formulation treated tissues. After $8 \mathrm{~h}$, the tissues were fixed in $10 \%$ formalin. For ex vivo histopathological examination, tissue sections were stained with hematoxylin and eosin. Tissue examination was done using light microscope.

\section{DISCUSSION}

Polymeric science needs to be explored to find newer mucoadhesive polymers with the added attributes of being biodegradable, biocompatible, non-toxic, mucoadhesive for specific cells or mucosa and which could also function as enzyme inhibitors for the successful delivery of proteins and peptides. Mucoadhesive drug delivery system proves to be an only alternative to conventional drugs by popular quality of its ability in overcoming hepatic metabolism, reduction in dose frequencies and enhancing bioavailability. Natural polymers used as mucoadhesive polymers. It facilitates an important tool to improve the bioavailability of the bioactive agent by improving the residence time at the delivery site. Improvement of novel natural mucoadhesive delivery systems are being undertaken so as to understand the various mechanism of mucoadhesion and improved permeation of active agents. Mucoadhesive drug delivery systems required to more work for the development of ideal mucoadhesive polymer which can deliver the drug very easily.Natural gums are promising biodegradable polymeric materials. Many studies have been carried out in fields, including food technology and pharmaceuticals using gums. Clearly gums have many advantages over synthetic materials. Various applications of gums have been established in the field of pharmaceuticals.

3. Kumar U, Lal K, Patel N, Lekhraj, Prakash J, Omkar, et al. Understanding the Concept of Mucoadhesive Drug Delivery System: A Novel Approach over Conventional Dosage Forms. Res. J. Pharma. Dosage forms and Tech,2018; 10(2):103108.

4. Duggan S, Cummins W, Donovan O, Hughes H. Thiolated polymers as mucoadhesive drug delivery system. Eur J Pharm Sci, 2017; 100: 2-19. 
5. Gandhi SD, Pandya PR, Umbarkar R, Tambawala T, Shah MA. Mucoadhesive drug delivery systemsan unusual maneuver for site specific drug delivery system. Int J Pharma Sci, 2011; 2(3): 132-152.

6. Chowdary KPR, Shrinivas L: Mucoadhesive Drug Delivery System: A Review of Current Status. Indian Drugs., 2000; 37(9): 400-405.

7. Peggs K, Mackinnon S. Imatinib mesylate, the new gold standard for treatment of chronic myeloid leukemia. N. Engl. J. Med, 2003; 348:1048-1050.

8. James Swarbrick, Encyclopedia of Pharmaceutical Technology, Third edition, 2, 11691179.

9. Kontogiorgos V, Margelou I, Georgiadis N, Ritzoulis C. Rhelolgical characterization of okra pectins. Food Hydrocolloids, 2012; 29: 356-362.

10. Siegel A, Rathbone M. Overview of Controlled Release Mechanisms. Adv. Deliv. Sci. Tech., 2012; 1:19-43.

11. Ghosh S, Kumar P, Bhanja S, Saha N, Tiwari S. Formulation and evaluation of mucoadhesive buccal tablets of montelukast sodium. Int. J. of Pharm Anal Res, 2018; 7(1): 10-15.

12. Good WR. Transdermal Nitrocontrolled Delivery of Nitroglycerin Via the Transdermal Route. Drug Dev Ind Pharm., 1983; 9:647-70.

13. Lee J. W, Park, J. H, Robinson J. R. Bioadhesivebased dosage forms: The next generation. J. Pharm. Sci, 2000; 89(7): 850-866.

14. Hagerstrom H, Edsman K, Stromme M. Low Frequency Dielectric Spectroscopy as a Tool for Studying the Compatibility between Pharmaceutical Gels and Mucus Tissue. J. Pharm. Sci, 2003; 92(9):1869-1881.

15. Boddupalli BM, Zulkar NK, Nath RA, Banji D. Mucoadhesive drug delivery system: An overview. J Adv Pharm Tech Res.,2010; 1(4): 381-387.

16. Aleksovski A, Dreu R, Gasperlin M, Planinsek O. Mini-tablets: a contemporary system for oral drug delivery in targeted patient groups. Expert Opin Drug Deliv.,2015; 12(1):65-84.

17. Smart J.D. The basics and underlying mechanisms of mucoadhesion. Adv. Drug Del. Rev,2005; 57(11): 1556- 1568.

18. Carvalho FC, Bruschi ML, Evangelista RC, Gremiao MPD. Mucoadhesive drug delivery systems. Pharm. Sci., 2010; 46(1): 1-18.

19. Saraswathi B, Balaji A, Umashankar MS. Polymers in mucoadhesive drug delivery system-
Latest updates. Int J Pharm Pharm Sci., 2013; 5(2):423-430.

20. Reineke J, Cho DY, Dingle YL, Cheifetz P, Laulicht B, Lavin D, et al. Can bio adhesive nanoparticles allow for more effective particle uptake from the small intestine?. J Control Release., 2013; 170(3):477-84.

21. Mathiowitz E. et al. Correlation of two bioadhesion assays: the everted sac technique and the CAHN microbalance. J. Control. Rel, 1999; 61(2): 113-122.

22. Shivhare UD, Mathur VB, Sort MW. Preparation and in-vitro evaluation of bioadhesive biodegredable antibiotic implant.Int J Biopharm, 2013; 4(3): 190-195.

23. Khan S, Verma M, Aggrawal G, Hari SL. Mucoadhesive drug delivery system: a review.World J Pharm Pharm Sci, 2016; 5(5): 392-405.

24. Nagaveni P, Sekhar C, Reddy J. Mucoadhesive drug delivery system - innovative approach and development.Int J Bio \& Pharm Res., 2017; 8(3): 117-122.

25. Pawar RR, Raut DB, Karde VK, Wadikar JC, Jadhav AS, Chintale AG. Mucoadhesive buccal delivery system: A review. Res J Pharm and Tech., 2013; 6(5): 506-515.

26. Mahajan P, Kaur A, Aggarwal G, Harikumar SL. Mucoadhesive Drug Delivery System: A Review. World J Pharm Res, 2013; 5(1):11-20.

27. Horstedt P, Danielsson A, Nyhlin H, Stenling R and Suhr O. Adhesion of bacteria to the human small intestinal mucosa. Scandinavian J. Gastroenterology, $1989 ; 24: 877-885$.

28. Peppas N A and Buri P A. Surface, interfacial and molecular aspects of polymer bioadhesion on soft tissues. J. Control. Release., 1985; 2:257-275.

29. Tangari P, Madhav NVS. Oral mucoadhesive drug delivery systems:A review. Int J Bio Pharm, 2011; 2(1):36-46.

30. Abolfazl A, Farnaz R. Medicated chewing gum, a novel drug delivery system. J Res Med Sci, 2015; 20(4):403-1.

31. Singh PK, Singh D, Bijauliya RK. A review on buccal drug delivery system. Int J Res Dev Pharm L Sci.,2017; 6(3):2608- 2618.

32. Nayak BS, Rout PK, Nayak UK, Bhowmik BB. Development and Characterization of Bio adhesive 
Gel of Microencapsulated Metronidazole for Vaginal Use. Iran J Pharm Res, 2010; 9(3):209-19.

33. Andrews GP, Laverty TP, Jones DS. Mucoadhesive plat forms for controlled drug delivery. Eup J Bio Pharm, 2009; 71(3):505-518.

34. Caon T, Jin L, Simoes CM, Norton RS, Nicolazzo JA. Enhancing the Buccal mucosal delivery of peptide and protein therapeutics. Pharm Res, 2015; 32(1):1-21.

35. Gilhotra RM, Ikram M, Srivastava S, Gilhotra N. A clinical perspective on mucoadhesive Buccal drug delivery systems. J Biomed Res, 2014; 28(2):81-97.

36. Morales JO, Mc Conville JT. Novel strategies for the Buccal delivery of macromolecules. Drug Dev Ind Pharm, 2014; 40(5):579-90.

37. Laffleur F. Mucoadhesive polymers for Buccal drug delivery. Drug Dev Ind Pharm, 2014; 40(5):5918 .

38. Laffleur F, Bernkop-Schnürch A. Strategies for improving mucosal drug delivery. Nanomedicine (Lond), 2013; 8(12):2061-75.

39. Gandhi RB, Robinson JR. Oral cavity as a site for bioadhesive drug delivery. Adv. Drug Deliv. Rev, 1994; 13:43-74.

40. Squier CA, Johnson NW, Hopps RM. The organization of oral mucosa, human oral mucosa, development, structure and function, Blackwell scientific Publications, Oxford, 7-15.

41. Chen SY, Squier CA. the ultrastructure of the oral epithelium, the structure and function of oral mucosa, Pergamon Press, Oxford, 1984;7-30.

42. Shojaei AH. Buccal Mucosa as a route for systemic drug delivery: a review. J. Pharm. Pharm. Sci., 1998; 1:15-30.

43. Harris D, Robinson JR. drug delivery via the mucous membranes of the oral cavity. J. Pharm. Sci., 1992; 81:1-10.

44.Zool A. Comparative Ultrastructure of Arthropod Transporting Epithelia. Ultrastructure of Arthropod Epithelia,1984; 24:139-156.

45. Meyer J, Gerson SJ. A comparison of human palatal and buccal mucosa. Periodontics, 1964; 2: 284-291.

46. Stablein MJ, Meyer J. The vascular system and blood supply, in: Meyer J, Squier Ca, Gerson SJ. The structure and function of oral mucosa, Pergamon Press, Oxford, 1984; 237-256.

47. Allen A, Bell A, McQueen. Mucus and mucosal protection, in: Allen A, Flamestrom G, Garner A,
Silen W, Turnberg LA. Mechanisms of mucosal protection in the upper gastointestinal tract, Raven Press, New York, 1984; 195-202.

48. Lehr CM. from sticky stuff to sweet receptorsachievements, limits and novel approaches to bioadhesion. Eur. J. Drug Metab. Pharmacokinet, 1996; 21: 139-148.

49. Pathak B, Kumar K. Buccal drug delivery system: a tool for the effective delivery of pharmaceuticals. Uni J Pharm Res., 2017; 2(3): 2025.

50. Haas J, Lehr CM. Developments in the area of bioadhesive drug delivery systems. Expert Opin. Biol. Ther,2002; 2:287-298.

51. Madhavi R, Murthy V, Rani P, Gattu D. buccal film drug delivery system- An innovative and emerging technology. J Mol Pharm Org Process Res, 2013; 1(3):1-6.

52. Elsner F, Zeppetella G, Porta-Sales J, Tagarro I. Newer generatin fentanly transmucosal products for breakthrough pain in opioid tolerant cancer patients. Clin. Drug Investig., 2011; 31(9): 605-618.

53. Datri S, Sruthi AS, Rao LA.Mucoadhesive Films - An Over Review. Asian J Sci Tech, 2017; 8(5):4790-4802.

54. Miller N, Chittchang M, Johnston TP. The use of mucoadhesive polymers in buccal Drug delivery. Adv Drug Deliv Rev, 2005; 57:1666-1691.

55. Rojanasakul Y, Wang LY, Bhat M, Glover DD, Malanga CJ, Ma JKH. The transport barrier of epithelia: a comparative study on membrane permeability and charge selectively on the rabbit. Pharm. Res., 1992; 9:1029-1034.

56. Khanna R, Agarwal SP, Ahuja A. Mucoadhesive buccal drug delivery: a potential alternative to conventional therapy, Int J Pharm Sci., 1998; 60(1), 1-11. 15.

57. Boateng JS, Auffret AD, Matthews KH, Humphrey MJ, Stevens HN, Eccleston GM. Characterisation of freeze-dried wafers and solvent evaporated films as potential drug delivery systems to mucosal surfaces. Int. J. Pharm.,2010; 389:24-31.

58. Cilurzo F, Cupone IE, Minghetti P, Selmin F, Montanari L. Fast dissolving films made of maltodextrins. Eur. J. Pharm. Biopharm.,2008; 70:895-900.

59. Khanna R, Agarwal S, Ahuja A. Preparation and evaluation of bioerodible buccal tablets containing clotrimazole. Int. J. Pharm, 138:67-73. 
60. Ghebre-Selassie I, Martin C. Pharmaceutical extrusion technology. Boca Raton (FL): CRC Press. 61. Repka MA, Battu SK, Upadhye SB, Thumma S, Crowley MM, Zhang F, Martin C, McGinity JW. Pharmaceutical applications of hot-melt extrusion: part II. Drug Dev. Ind. Pharm.,2007; 33:1043-1057.

62. Morales JO, McConville JT. Manufacture and characterization of mucoadhesive buccal films. Eur. J. Pharm. Biopharm.,2011; 77:187-199.

63. Cilurzo F, Cupone IE, Minghetti P, Selmin F, Montanari L. Fast dissolving films made of maltodextrins. Eur. J. Pharm. Biopharm.,2008; 70:895-900.

64. Nafee NA, Ismail FA, Boraie NA, Mortada LM. Mucoadhesive buccal patches of miconazole nitrate: in vitro/ in vivo performance and effect of ageing. Int. J. Pharm.,2013; 264:1-14.

65. Roy S, Pal K, Anis A, Pramanik K, Prabhakar B.Polymers in Mucoadhesive Drug Delivery System: A Brief Note. Designed Monomers and Polymers, 2009; 12: 483-495.

66. Verma S, Kaul M, Rawat A, Saini S. An overview on buccal drug delivery system. Int J Pharm Sci Res.,2011; 2(6): 1303-1321.

67. Choi NW, Mori I, Ohama Y. Development of rice husks-plastics composites for building materials. Waste Manage.,2006; 26: 189-194.

68. Schneider JP, Myers GE., Clemons CM. English B. Biofibres as rein-forcing fillers in thermoplastic composites. Eng. Plast,1995;8 (3), 207.

69. Colberg M., Sauerbier M. Injection moulding of natural fibre-rein-forced plastics. Kunststoffe Plast Europe., 1997; 87 (12), 9.

70. Schloesser T., Knothe J. Vehicles parts reinforced with natural fibres. Kunststoffe PlastEurope.87(9), 25.

71. Choudhary PD, Pawar HA. Recently Investigated Natural Gums and Mucilages as Pharmaceutical Excipients: An Overview. J Pharma.,2014; 1-9.

72. Schnurch AB. Mucoadhesive polymers: Strategies, achievements and future challenges. Adv Drug Deliv Rev, 2005; 57(11):1553-1555.

73. Heer D, Aggarwal G, Kumar SH. Recent trends of fast dissolving drug delivery system - an overview of formulation technology. Pharmacophore., 4:1-9.

74. . Ishida M, Machida Y, Nambu N, Nagai T. New Mucosal Dosage Form Of Insulin. Chem. Pharm.

Bull, 1981; 29:810-816.
75. Nagai T, Machida Y. Advances In Drug Delivery- Mucosal Adhesive Dosage Forms. Pharm. Int., 1985; 6:196-200.

76. Yang X, Robinson JR. Bioadhesion in Mucosal Drug Delivery. In: Okano T, editor. Biorelated Polymers and Gels. London: Academic Press.,1998; 135-192.

77. Mythri .G K, Kavitha M. Kumar R, Singh J. Novel Mucoadhesive Polymers -A Review, J Applied Pharm Sci, 2011; 01(08):37-42.

78. Anil A., Sudheer P. Mucoadhesive polymers: A review. Journal of Pharmaceutical Research, 2018; 17(1): 47-55.

79. Goswami S. Natural gums and its pharmaceutical application. J Sci and Innov Res, 2014; 3(1): 112-121.

80. Shirwaikar A, Prabu SL, Kumar GA. Herbal excipients in novel drug delivery systems. Ind $\mathrm{J}$ Pharm Sci, 2008; 70:415-22.

81. Shiledar RR, Tagalpallewar AA, Kokare CR. Formulation and in vitro evaluation of xanthan gumbased bilayered mucoadhesive buccal patches of zolmitriptan, Carbohydr. Polym., 2014; 101:1234-42. 82. Cilurzo F, Cupone IE, Minghetti P, Selmin F, Montanari L. Fast dissolving films made of maltodextrins. Eur. J. Pharm. Biopharm., 2008;70:895-900.

83. Mandal S, Thimmasetty J, Ratan GN, Kilarimath BH. Formulation and evaluation of carvedilol transdermal patches. Int Res J Pharm., 2011; 2(1): 237-248.

84. JelvehgariM., ValizadehH., ZiapourS., RahmaniM., MontazamSH., SoltaniS. Comparative study of different combinational mucoadhesive formulations of sumatriptan-metoclopramide, Adv. Pharm. Bull., 2016; 6:119-30.

85. Adhikari SNR, Nayak BS, Nayak AK, Mohanty B. Formulation and evaluation of buccal patches for delivery of atenolol. AAPS PharmSciTech., 2010; 11:1038-1044.

86. Al-DhubiabBE., NairAB., KumriaR., AttimaradM., HarshaS.Development and evaluation of buccal films impregnated with selegiline-loaded nanospheres, Drug. Deliv., 23:2154-62, 2004.

87. Rana P, Murthy RS. Formulation and evaluation of mucoadhesive buccal films impregnated with carvedilol nanosuspension: a potential approach for delivery of drugs having high 
first-pass metabolism, Drug. Deliv., 20:224-35, 2013.

88. Nair AB, Kumria R, Harsha S, Attimarad M, Al-Dhubiab BE, Alhaider IA. In vitro techniques to evaluate buccal films, J. Control. Release., 166:10$21,2013$.

89. Morales JO., SuR., McConvilleJT.The influence of recrystallized caffeine on waterswellable polymethacrylate mucoadhesive buccal films, AAPS. PharmSciTech., 14:475-84, 2013.

90. Chun MK, Kwak BT, Choi HK. Preparation of buccal patch composed of carbopol, poloxamer and hydroxypropyl methylcellulose. Arch. Pharm. Res., 26:973-978, 2003.
91. R Kumria, AB. Nair, BE. Al-Dhubiab, Loratidine buccal films for allergic rhinitis: development and evaluation, Drug. Dev. Ind. Pharm., 40:625-31, 2014.

92. Shidhaye SS, Saindane NS, Sutar S, Kadam V. Mucoadhesive bilayered patches for administration of sumatriptan succinate, AAPS. Pharm Sci Tech., 9:909-16, 2008.

93. Majithiya RJ, Ghosh PK, Umrethia ML, Murthy RS. Thermoreversible-mucoadhesive gel for nasal delivery of sumatriptan. PharmSciTech. 7:E1-E7, 2006. 